\title{
The Demand for Fertility Control in Pakistan
}

\author{
NAUSHIN MAHMOOD and G. M. ZAHID
}

The shift from high to low fertility during the process of modernisation may occur through a reduction in the demand for children and an increase in deliberate fertility control behaviour of individuals. This, in turn, depends on couple's positive attitudes and willingness to adopt contraception and the easy availability and accessibility of the means of fertility regulation. In social settings like Pakistan where the desire for large family size exists and deliberate family limitation is not very common, it is of great importance to study the process of making family size choices and assess the demand for fertility control which are very likely to influence the future prospects of fertility change. A recent study in reviewing population policy and family planning programme effectiveness in a number of Third World countries including Pakistan has stressed on the immediate need to estimate the potential demand for services and the extent of such demand in specific areas and subgroups of population [Freedman (1987)]. The findings from WFS data on fertility desires for many developing countries also suggest that if women fully implement their stated desire for children and restrict themselves to wanted births, substantial decline in fertility is likely to occur in a majority of countries and unlikely in only a few [Lightbourne (1988)]. Such findings are important in the context of Pakistan's fertility situation where a significant number of women want to stop childbearing and speculation about a substantial decline in fertility exists.

Different approaches have been used in the past to estimate the demand for fertility control taking into account women's desire for children and/or their number of living children. The term 'demand' used in this study broadly refers to the latent desire of women in their childbearing years to limit future births, which we may call the 'potential demand' for fertility control. The focus of this paper is to see how much demand for family limitation exists among various strata of population which in turn, has implications for deliberate fertility control bẹhaviour. The paper first assesses different measures of family planning demand as derived from Easterlin's $(1975,1978)$, framework of fertility determination and then determines which of these measures largely explain variations in contraceptive use. Such an analysis can give us some understanding of how a woman's given supply of children and her 
demand for children are related to her fertility control behaviour, and can also give some indication of the potential target groups for family planning services.

The data base used for the analysis is mainly drawn from three KAP surveys namely the Pakistan Fertility Survey of 1975 (PFS); the Population, Labour Force and Migration Survey (PLMS) of 1979-80; and the Pakistan Contraceptive Prevalence Survey (PCPS) of 1984-85, and some information from the Pakistan Demographic and Health Survey (PDHS) of 1990-91 to indicate the most recent estimates. Although these surveys differ in terms of their sample design, methodology, quality of enumeration, the sampling and non-sampling errors, they are quite comparable in concepts and the measurement of variables used in the analysis. The survey responses on desired fertility over different years have persistently indicated that a significant proportion of married women do not want more children and a majority of these women are not protecting themselves in all population strata [Mahmood (1992)]. This provides an important basis for identifying potential demand for family planning services.

Deriving from Easterlin's theoretical model of fertility regulation, the transition from natural to controlled fertility works through three main variables: (1) the demand for children $\left(C_{d}\right)$, taken to be as the number of surviving children a woman desires; (2) the supply of children $\left(C_{n}\right)$, corresponding to the number of surviving children a woman would have if no fertility limitation was practiced; and (3) the costs of fertility regulation $\left(R_{c}\right)$, including both subjective and market costs associated with deliberate fertility control. These variables, in turn, are determined by a set of socio-economic and demographic factors [for fuller details of the model and a discussion of related issues, see Bulatao and Lee (1983); Easterlin (1975, 1978); Easterlin and Crimmins (1985).

According to this framework, it is plausible that a couple may want to practice family planning when their number of surviving children exceeds their demand for children. Conversely, a couple will have no incentive to limit fertility if they are unable to achieve their desired number of children. Thus, the greater $C_{n}$ (number of surviving children) is in excess of $C_{d}$ (number of desired children), the greater is the potential burden of unwanted children, implying an increased demand for fertility control and a greater likelihood of contraceptive use.

\section{FAMILY PLANNING DEMAND}

Among various indicators, the simplest direct measure of family planning demand, based on surveys, is the proportion of women who say they want no more children. Although such data are not perfect and have certain limitations, yet have proved to be useful in indicating a potential demand for children and fertility control [Easterlin (1988)].

Another measure compares the desired number of children with the actual and expected number. In most countries where large scale family planning adoption has occurred, systematic evidence shows that the number of surviving children for a majority of couples was in excess of those desired [Freedman (1987)]. 
Apart from these two basic measures, the number of surviving children a couple would have in the absence of contraceptive use ${ }^{1}$ and the number of desired children can also be considered approximate indicators of family planning demand chiefly because they are components of the preceding measure and are closely related with contraceptive use. The expectation is that the larger the number of living children, the greater is the probability of contraceptive adoption. On the other hand, desire for children is expected to vary inversely with contraceptive use.

To test Easterlin's hypothesis of fertility regulation, we begin our analysis by presenting a summary of results on fertility, desired family size and contraceptive use drawn from four cross-sectional surveys of 1975 (PFS), 1979-80 (PLM), 198485 (PCPS), and 1990-91 (PDHS) to indicate variability in fertility and family planning-related behaviour of women (see Table 1).

\section{Table 1}

Fertility Levels, Desired Family Size, Contraceptive Use and Percent Wanting No More Children in Different Years, for Urban and Rural Areas of Pakistan

\begin{tabular}{|c|c|c|c|c|c|c|c|c|}
\hline \multirow[b]{2}{*}{$\begin{array}{l}\text { Year of } \\
\text { Survey }\end{array}$} & & \multirow[b]{2}{*}{ ATFR } & \multirow[b]{2}{*}{ CEB } & \multicolumn{2}{|c|}{$\begin{array}{l}\text { Desired Family } \\
\text { Size (Mean) }\end{array}$} & \multicolumn{2}{|c|}{$\begin{array}{c}\% \text { Using } \\
\text { Contraceptive }\end{array}$} & \multirow{2}{*}{$\begin{array}{l}\text { Percent } \\
\text { Wanting } \\
\text { No More } \\
\text { Children }\end{array}$} \\
\hline & & & & $<35$ & $\begin{array}{c}\text { All } \\
\text { Ages }\end{array}$ & Ever & Current & \\
\hline \multicolumn{9}{|c|}{ All Palistan } \\
\hline $1974-75$ & (PFS) & 6.3 & 4.2 & 4.0 & 4.4 & 10.5 & 5.2 & 49.4 \\
\hline $1979-80$ & (PLMS) & 6.5 & 4.1 & 4.3 & 4.5 & 6.0 & 4.1 & 39.5 \\
\hline $1984-85$ & (PCPS) & 6.0 & 4.3 & 4.5 & 4.9 & 11.8 & 9.1 & 43.4 \\
\hline $1990-91$ & (PDHS) & 5.4 & 4.1 & $3.9^{*}$ & 4.1 & 20.7 & 14.0 & 36.4 \\
\hline \multicolumn{9}{|c|}{ Urban Areas } \\
\hline $1974-75$ & (PFS) & 6.2 & 4.2 & - & 3.9 & 21.9 & 12.4 & 54.0 \\
\hline $1979-80$ & (PLMS) & 6.2 & 4.4 & 4.2 & 4.3 & 11.1 & 7.7 & 48.8 \\
\hline $1984-85$ & (PCPS) & 5.6 & 4.4 & 4.4 & 4.9 & 28.6 & 18.1 & 49.4 \\
\hline $1990-91$ & (PDHS) & 4.9 & - & $3.6^{*}$ & 3.7 & - & $25.7^{* *}$ & 52.3 \\
\hline \multicolumn{9}{|c|}{ Rural Areas } \\
\hline $1974-75$ & (PFS) & 6.4 & 4.1 & - & 4.3 & 6.3 & 2.7 & 47.0 \\
\hline $1979-80$ & (PLMS) & 6.6 & 3.9 & 4.6 & 4.7 & 7.0 & 5.7 & 41.0 \\
\hline 1984-85 & (PCPS) & 6.1 & 4.2 & 4.7 & 5.0 & 7.0 & 5.4 & 41.0 \\
\hline $1990-91$ & (PDHS) & 5.6 & - & $4.2^{*}$ & 4.3 & - & $5.8^{* *}$ & 34.6 \\
\hline ources: & $\begin{array}{l}\text { Pakistan } \\
\text { Pakistan } \\
\text { Survey ( } \\
\text { Ideal Fan }\end{array}$ & $\begin{array}{l}\text { iility S } \\
\text { ntracep } \\
\text { o-91). } \\
\text { Size. }\end{array}$ & 197 & Popula & abou & $\begin{array}{l}\text { orce } \\
\text { d } \mathrm{Pa}\end{array}$ & $\begin{array}{l}\text { Migratio } \\
\text { an Demo }\end{array}$ & $\begin{array}{l}\text { ley }(1979-80) \\
\text { ic and Health }\end{array}$ \\
\hline
\end{tabular}

'Since a majority of women in Pakistan experience natural fertility with no deliberate effort to limit births, the actual number of surviving children can be approximated for the potential number of births a woman would have during her reproductive years. 
Table 1 indicates clearly that despite high levels of fertility and desired family size, the proportion of women wanting no more children ranges between 40 and 50 percent, while both ever and current contraceptive use have been much below the expected or desired level, particularly in rural areas. The discrepancy between the expressed desire for no more children and not practicing birth control is important in terms of estimating family planning demand and evaluating the programme's effectiveness.

In order to note the differences in the demand for fertility control by age, Table 2 presents the mean number of living children $(C)$, desired children $\left(C_{d}\right)$ and unwanted children $\left(C-C_{d}\right)$ along with percentages wanting no more.children (WNM) and contraceptive use (both ever and current) for the age groups 25-34 and $35-44$ of currently married women. The relatively younger women $(25-34)$ who are still in the process of completing their fertility goals and the older women (35-44) who are close to the end of their reproductive careers can serve as useful potential target groups for family planning programme intervention if they indicate a positive demand for fertility control.

The results in Table 2 indicate no significant variation in the number of living and desired children for both age groups of women with some change in contraceptive use. This is consistent with the findings in both Thailand and Taiwan

\section{Table 2}

Mean Number of Living Children (C), Desired Children (Cd) and Unwanted Children $C-C_{d}$; and Percentage Wanting No More (WNM) and Using Contraceptives, Currently Married Women Aged 25-34 and 35-44:

$$
\text { 1974-75 - 1990-91 }
$$

\begin{tabular}{|c|c|c|c|c|c|c|c|}
\hline \multirow[b]{2}{*}{$\begin{array}{l}\text { Year of } \\
\text { Survey }\end{array}$} & & \multirow{2}{*}{$\begin{array}{l}\text { Living } \\
\text { Children } \\
(C)\end{array}$} & \multirow{2}{*}{$\begin{array}{c}\text { Desired } \\
\text { Children } \\
\left(C_{d}\right)\end{array}$} & \multirow{2}{*}{$\begin{array}{c}\text { Unwanted } \\
\text { Children } \\
\left(C-C_{d}\right)\end{array}$} & \multirow{2}{*}{$\begin{array}{c}\text { Want } \\
\text { No More } \\
\text { (WNM) }\end{array}$} & \multicolumn{2}{|c|}{ Contraceptive Use } \\
\hline & & & & & & (Ever) & (Current) \\
\hline \multicolumn{8}{|c|}{ Women Aged 25-34 } \\
\hline $1974-75$ & (PFS) & 3.4 & 4.1 & -0.7 & 46.9 & 14.7 & 7.5 \\
\hline $1979-80$ & (PLMS) & 3.3 & 4.6 & -1.3 & 44.8 & 7.1 & 4.6 \\
\hline $1984-85$ & (PCPS) & 3.4 & 4.9 & -1.5 & 37.3 & 13.9 & 8.2 \\
\hline $1990-91$ & (PDHS) & 3.4 & $4.1^{*}$ & -0.7 & 31.4 & 21.2 & 11.3 \\
\hline \multicolumn{8}{|c|}{ Women Aged 35-44 } \\
\hline $\begin{array}{l}1974-75 \\
1979-80\end{array}$ & $\begin{array}{l}\text { (PFS) } \\
\text { (PLMS) }\end{array}$ & $\begin{array}{l}4.9 \\
4.9\end{array}$ & $\begin{array}{l}4.2 \\
4.8\end{array}$ & $\begin{array}{l}0.7 \\
0.1\end{array}$ & $\begin{array}{l}58.0 \\
55.2\end{array}$ & $\begin{array}{r}18.0 \\
8.6\end{array}$ & $\begin{array}{l}9.5 \\
6.1\end{array}$ \\
\hline $1984-85$ & (PCPS) & 5.3 & 5.4 & -0.1 & 72.9 & 18.2 & 12.4 \\
\hline $1990-91$ & (PDHS) & 5.3 & $4.3^{*}$ & 1.0 & 58.3 & 29.2 & 18.3 \\
\hline
\end{tabular}

Source: As in Table 1.

*The figures correspond to ideal family size because direct estimate of desired number of children are not available in PDHS. 
where the early rise in contraceptive use occurred while the desired number of children remained stable [Freedman (1987)]. A positive value of $C-C d$ for relatively older age group (35-44) of women indicates that these women after completing their fertility goals have experienced excess births and should be considered as potential target group for programme services. Although the correspondence between the desire for no more children and actual use of fertility control is low among both age groups of women, the difference is greater among older women. This implies that most women who have achieved their fertility goals have either not been contacted by the programme personnel or if contacted, have not adopted contraception for some reason. This is an important subject of further inquiry and needs to be understood with more detailed information. However, these results do suggest that with the limited programme resources and its outreach, it would be worthwhile to concentrate on women with three or more children in the age group of 35-44 years, who have indicated a higher family planning demand than younger women.

\section{FACTORS EXPLAINING VARIATIONS IN FERTILITY CONTROL}

After examining the trends and variations in family planning demand variables and their correspondence with contraceptive use, a multivariate analysis is undertaken to study the extent of relationship of these variables with actual use after taking into account women's education, place of residence and accessibility to the programme services. The dependent variable for this analysis is contraceptive use, measured as a dichotomous variable taking the value of one if a woman reported ever using contraceptives and zero otherwise. ${ }^{2}$ Logit regressions are used to estimate the effect of each explanatory variable on contraceptive use in the form written as:

$$
L=\log P(1-P)=\log P-\log (1-P)=X B
$$

where $L$ is the logit or the $\log$ of the odds ratio. The logits, as opposed to proportions, will give coefficients bounded by zero or one in the probability metric. The estimated coefficients which have positive and negative signs indicate the increment in the log-odds of contraception with a unit change in the explanatory variable.

The independent variables include number of living children $(C)$, desired children $\left(C_{d}\right)$, a combination of living and desired children $\left(C=C_{d}\right.$ and $\left.C>C_{d}\right)$, wanting no more children (WNM), women's education (WED), place of residence $(u r b)$, and access to family planning services $(A F P)$. The definition and

\footnotetext{
${ }^{2}$ Ever-use is the dependent variable in this study because it is a more relevant variable than current use in explaining a women's cumulative fertility which is an important policy goal in the context of the present analysis.
} 
measurement of these variables is described below. ${ }^{3}$ Regression equations are estimated for the analysis of contraceptive use on each set of explanatory variables, including family planning accessibility variable and results are compared for each data set in Table 3.

\section{Table 3}

Logit Regression Results of the Effect of Specified Variables on Ever-use of Contraception, Three Surveys, 1975, 1979-80 and 1984-85

(Currently Married Women Aged 35-44 Years)

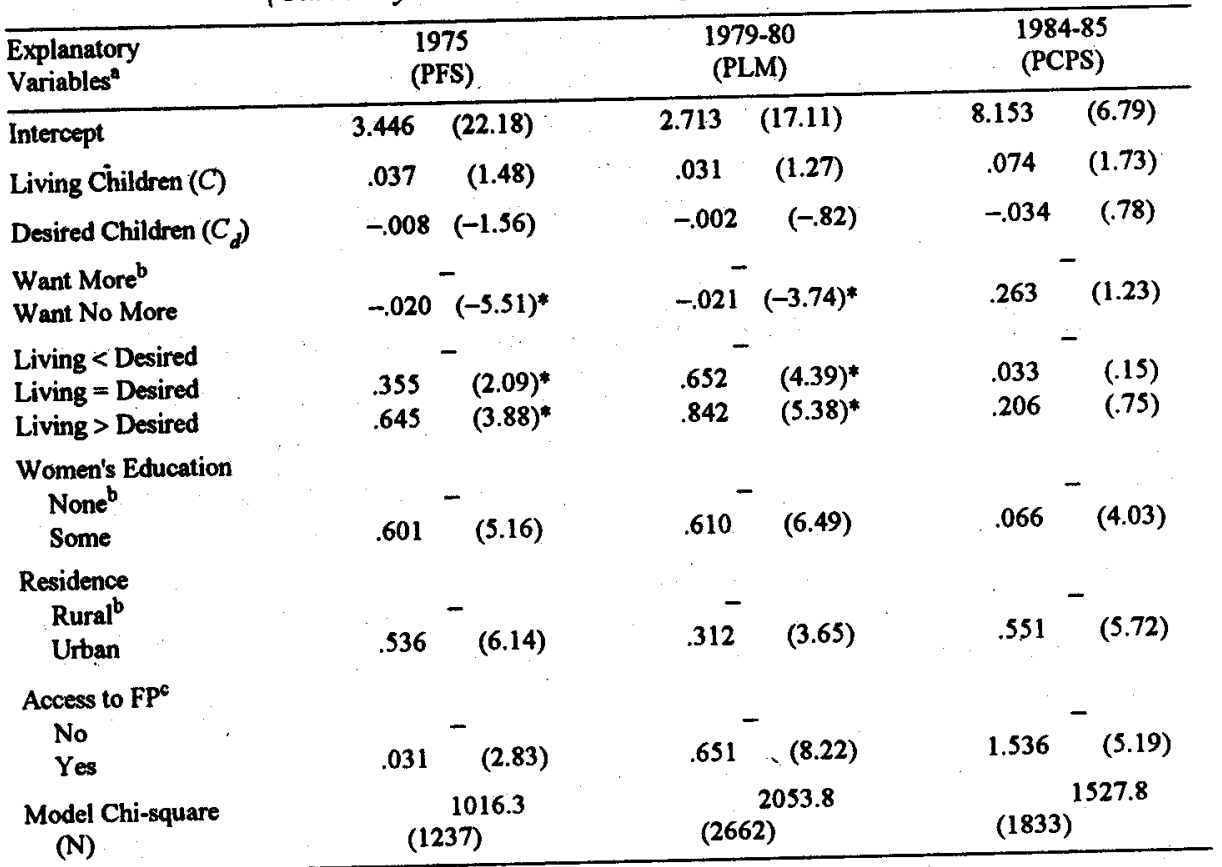

Note: $\mathrm{t}$-statistics in parenthesis.

the definition and measurement of variables is given in footnote 2.

breference category

access to family planning. For this specific measure in PFS and PLM surveys, the variable 'met planning worker' is used as an indicator of accessibility, whereas in PCPS the variable whether it is 'easy' or 'difficult' to reach a service outlet is used as a proxy for accessibility. These were the best possible measures tried for FP availability and accessibility in each survey.

${ }^{3}$ Measures of Explanatory variables:

C : number of living children;

$C_{d} \quad:$ desired number of children;

WNM : 1 if a woman is fecund and wants more children, otherwise $=0$;

$C=C_{d} \quad: \quad 1$ if a woman's number of living children equals her desired number, otherwise $=0$;

$W E D$ : 1 if a woman has some education, otherwise $=0$;

Urb : 1 if a woman lives in urban areas, otherwise $=0$; and

AFP : 1 if a woman has met a family planning person, otherwise $=0$. 
The subsample selected for this analysis comprises currently married women aged 35-44 years, who are close to the end of their reproductive period and have indicated relatively higher family planning demand than younger age groups.

Our results in Table 3 for most of the variables are in the expected direction. Women's education, urban residence and family planning accessibility are significant in increasing the likelihood of contraceptive use in all surveys. Among the family planning demand indicators, however, the extent of relationship with actual use varies among surveys. The number of living and desired children have expected signs but do not explain variation in contraceptive use significantly. This implies that the two variables independently are not influential in turning the potential demand into effective demand for fertility regulation. Regarding the balance between living and desired children, the magnitude of the effect varies among surveys showing the lowest performance in the 1984-85 (PCPS) survey. For example, the excess fertility variable (living $>$ desired) is significant in increasing the likelihood of use in 1975 and 1979-80 surveys, and insignificant in the 1984-85 survey. These results also make it evident that most of those women who want no more children are not protecting themselves as indicated by the negative signs of the coefficients in all surveys. This is an important question to address in the context of Pakistan's present social and economic structure in which a reluctance to adopt fertility control behaviour even among those women who say that they want no more children in combination with a limited outreach of the programme probably weaken the motivation for contraceptive use.

Overall, these results show that the demand indicators studied in this analysis do not reveal a strong and consistent pattern of relationship with contraceptive use. However, education, urban residence and access to family planning personnel are better measures of explaining variation in contraceptive use with consistent results in all surveys.

\section{CONCLUDING REMARKS}

The results of our analysis from four cross-sectional surveys uniformly point to high levels of fertility, desired family size and low contraceptive use. Based on surveys, estimates, we found that a substantial proportion of currently married women above age 35 report that they want no more children, (between 50 and 60 percent) only a small minority of these women are users of contraception, leaving a large gap between the potential demand for and actual use of contraception. This gap could either be due to personal or normative constraints on adoption of fertility control, or due to supply related problems of family planning services.

Our results also indicate that there is no significant change in the demand measures overtime while contraceptive use has gradually risen, still remaining much below the expected level. This is evident from the large gap observed in proportion WNM and actual practice of family planning. Greater efforts are therefore needed to reach those women who demonstrate a high demand for family 
planning. Our results do suggest that it would be worthwhile to concentrate on women with three or more children in the age group of 35-44 years who appear to have achieved their fertility goals and have experienced unwanted births.

The role of family planning demand measures in explaining variation in contraceptive use is unclear and does not show a consistent and strong relationship with use in all surveys overtime. However, if lower fertility is a social policy goal, then it is important to have periodic assessment of demand through surveys, together with the provision of organised and high quality services according to the clients' needs.

As expected, our results confirm that women's education, urban residence and access to programme services are important in promoting contraceptive use. In sum, even if increased programme efforts are likely to turn potential demand into actual use, there is little doubt that increase in the levels of education and hence, more economic and social opportunities for women can be effective in the promotion of smaller family size norms and deliberate fertility regulation.

\section{REFERENCES}

Bulatao, R. A., and R. D. Lee (eds) (1983) Determinants of Fertility in Developing Countries: A Summary of Knowledge. New York: Academic Press.

Easterlin, Richard A. (1975) An Economic Framework for Fertility Analysis. Studies in Family Planning 6:3.

Easterlin, Richard A. (1978) The Economics and Sociology of Fertility: A Synthesis. In Charles Tilly (ed) Historical Studies of Changing Fertility.

Princeton: Princeton University Press.

Easterlin, R. A., and E. M. Crimmins (1985) The Fertility Revolution: A Supply-

Demand Analysis. Chicago: University of Chicago Press.

Easterlin, R. A., K. Wongboonsin and M. Aly Ahmed (1988) The Demand for

Family Planning: A New Approach. Studies in Family Planning 19:5.

Freedman, Ronald (1987) The Contribution of Social Science Research to

Population Policy and Family Planning Programme Effectiveness. Studies in

Family Planning 18:2.

Lightbourne, Robert (1988) New Approaches for Estimating the Demand for

Children. Population Bulletin of the United Nations 23/24. New York:

Department of International Economic and Social Affairs.

Mahmood, Naushin (1992) Motivation and Fertility Control Behaviour in Pakistan.

The Pakistan Development Review 31:2. 
The paper on "The Demand for Fertility Control in Pakistan" by Naushin Mahmood and G. M. Zahid which applies Easterlin's Model of Fertility Regulation-the transition from natural to controlled fertility is to be commended as an analytical effort to see how much demand for family limitation exists among various strata of Pakistani society.

Affected as most papers are by the dearth of up-to-date data, this paper is based primarily on:

(i) The Pakistan Fertility Survey (PFS-1975);

(ii) Population, Labour Force and Migration Survey (PLMS) (1979-80); and

(iii) Pakistan Contraceptive Prevalence Survey (PCPS) (1984-85).

Some data from the recent Pakistan Demographic and Health Survey (PDHS) (1990-91) are also used.

The authors of the paper do refer to differences in these surveys in terms of sample design, methodology, quality of enumeration and sampling non-sampling errors in the early part of paper, but do not take these differences into account while using the findings of the surveys for analysis of demand of family planning. Instead, the findings are taken at their face value. For example, the basic measure of family planning demand-WNM i.e. the percentage of women "wanting no more children". (In the paper under reference, given in Table 1, last column) which varies from 49.4 percent in the PFS (1975)-i.e., eighteen years back from today, to 36.4 percent in the recent PDHS (1990-91) is taken at its face value despite the reported rise in the contraceptive use (1990-91) rate to 20.7 percent in the PDHS compared with 10.5 percent in the PFS (1974-75), and the expectation that with the continued IEC efforts of the Population Welfare Programme the proportion of women "wanting no more children" will rise.

Similarly, equating the prevalent high levels of fertility among the majority of the Pakistani women to their 'natural fertility' in the paper requires on in-depth look.

Much of the analysis in the paper is focused on relatively older age groups of women (35-44) for whom a positive value of $C-C_{d}$ (Table 2 of the paper) is interpreted as "excess births" and, therefore, they are called the 'potential target group' for Population Welfare Programme services. Given the low marriage age of 
women in Pakistan, the emphasis on having children soon after marriage, and, the higher age-specific fertility in ages 20-29, women in the earlier age brackets need much more attention to reduce the overall fertility level.

Jamila Naeem

Ministry of Population Welfare.

Islamabad. 